\title{
BREVES REFLEXIONES SOBRE LAS MEDIDAS DE EMERGENCIA IMPLEMENTADAS POR ALGUNOS ESTADOS Y LA VIGENCIA DE LOS DERECHOS HUMANOS (DDHH) ANTE EL COVID-19
}

\author{
BRIEF REFLECTIONS ON THE EMERGENCY MEASURES IMPLEMENTED BY \\ SOME STATES AND THE VALIDITY OF HUMAN RIGHTS (HR) REGARDING \\ COVID-19
}

\author{
Maria Fatima Pinho de Oliveira ${ }^{1}$
}

\section{RESUMEN}

La pandemia del COVID-19, tras su aparición en Asia, ha presentado un gran repunte en Europa y en menor grado en América Latina. Las normas del Derecho Internacional de los Derechos Humanos garantiza que todas las personas disfruten del derecho de salud y obliga a los gobiernos a adoptar medidas para prevenir las amenazas a la salud pública y brindar atención médica a quienes la necesitan; y bajo esta amenaza de emergencia y salud pública las restricciones a algunos derechos pueden justificarse siempre y cuando cumplan con criterios establecidos internacionalmente. En este breve ensayo se presentan algunos planes tomados por los gobiernos de algunos países de América Latina como parte de las estrategias para aminorar la propagación del COVID-19. La metodología aplicada se basa en las diferentes opiniones realizadas por organismos internacionales publicados en la web, se analizan algunos derechos humanos y se reflexiona sobre las medidas implementadas por algunos Estados. En estos momentos, los grupos vulnerables (refugiados y migrantes) que se encuentran en campos masificados, corren un mayor riesgo de contagiarse, por lo tanto urge que los Estados los protejan.

Palabras clave: Derechos humanos, derecho internacional, COVID-19, crisis sanitaria y planes de Emergencia.

\begin{abstract}
The COVID-19 pandemic, after its appearance in Asia, has shown a great rebound in Europe and to a lesser extent in Latin America. The norms of International Human Rights Law guarantee that all people enjoy the right to health and compel governments to adopt measures to prevent threats to public health and provide medical care to those who need it; and under this threat of emergency and public health, restrictions on some rights may be justified as long as they meet internationally established criteria. This brief essay presents some plans taken by the governments of some Latin

\footnotetext{
1 Abogado (USM). Especialista y Magister en Derecho Penal. Profesora Asociado adscrita al Departamento de Ciencias Económicas y Administrativas de la Universidad Simón Bolívar. Doctorando en Derecho Internacional Publico de la Universidad Latinoamericana y del Caribe (ULAC). Areas de trabajo Derecho Internacional, Comercio Exterior, Administración Aduanera, Sociologia Juridica y Politica.Universidad Simón Bolívar - Camuri Grande. Venezuela. ORCID: https://orcid.org/0000-0002-7539-5620 E-mail: mpinho@usb.ve
} 
American countries as part of the strategies to lessen the spread of COVID-19. The applied methodology is based on the different opinions made by international organizations published on the web, some human rights are analyzed, and the measures implemented by some States are reflected on. At this time, vulnerable groups (refugees and migrants) who are in overcrowded camps are at a higher risk of becoming infected, therefore it is urgent that States protect them.

Keywords: Human rights, international law, COVID-19, health crisis and Emergency plans.

\section{INTRODUCCIÓN}

En diciembre de 2019 en Wuhan, China, se conoció la noticia de un brote de enfermedad por coronavirus (COVID-19). Para el 11 de marzo de 2020, la Organización Mundial de la Salud (OMS), declaró que había alcanzado el nivel de pandemia mundial y le solicitó a los gobiernos que tomasen medidas urgentes y contundentes para detener la propagación del virus.

En cuanto al Derecho Internacional, las normas que contienen los Derechos Humanos, garantizan que todas las personas disfruten del derecho de salud y obligan a los gobiernos a adoptar medidas para prevenir las amenazas a la salud pública y brindar atención médica a quienes la necesitan; y bajo esta amenaza de emergencia y salud pública las restricciones a algunos derechos pueden justificarse siempre y cuando cumplan con los siguientes criterios: que tengan una base legal, sean estrictamente necesarias según evidencias científicas y no sean arbitrarias ni discriminatorias en su aplicación, sean de duración limitada, respeten la dignidad humana, estén sujetas a revisión y sean proporcionales para lograr su objetivo.

Sin duda, la pandemia del COVID-19, asciende efectivamente, al nivel de una amenaza a la salud pública que, para garantizar el derecho a la salud, podría justificar restricciones a ciertos derechos, como los que resultan de la imposición de la cuarentena o el aislamiento y que limitan la libertad de tránsito o movimiento. Así mismo, una esmerada atención a derechos humanos como la no discriminación y principios de los derechos humanos como la transparencia y el respeto a la dignidad humana, puede fomentar una respuesta efectiva en medio de la agitación y los trastornos que inevitablemente resultan en tiempos de crisis, además de limitar los daños que provengan de la imposición de medidas muy generales que no cumplan con los criterios anteriores. (HUMAN RIGHTS WATCH, 2020).

Las oficinas de Naciones Unidas, la Comisión Interamericana de Derechos Humanos, la Organización para la Seguridad y la Cooperación en Europa, la Organización Mundial de la Salud, la Organización Panamericana de la Salud y Access Now, ante la pandemia de COVID-19, recomiendan a los gobiernos, que a través de la implementación de planes e intervenciones 
fundamentadas en el respeto a los derechos humanos y las garantías digitales, deben proteger la vida de los ciudadanos.

Los organismos mencionados en el párrafo anterior, han mostrado su preocupación por el control de las libertades en los decretos de emergencia, las medidas de censura, la penalización de las opiniones en internet y la desinformación que se ha esparcido en entornos digitales y comunitarios a la par del nuevo coronavirus; donde la prioridad es la salvaguarda del derecho a la salud, el acceso al servicio de agua, el amparo de los migrantes, el respeto a las libertades informativas, la protección de datos personales y los derechos digitales. (CHIRINOS, 2020).

En estas breves líneas se presenta un análisis de la vigencia de los DDHH en el marco de los diferentes planes de Emergencia que han aplicado los Estados con motivo del COVID-19, mencionando algunos derechos humanos y reflexionando sobre las medidas implementadas por algunos Estados.

\section{NORMAS DE DERECHO INTERNACIONAL APLICABLES}

De conformidad con lo establecido en el Pacto Internacional de Derechos Económicos, Sociales y Culturales, adoptado por la mayoría de los países, todas las personas tienen derecho al “más alto nivel posible de salud física y mental” y los gobiernos están obligados a tomar medidas efectivas para "la prevención, el tratamiento de las enfermedades epidémicas, endémicas, profesionales y de otra índole, y la lucha contra ellas”. (HUMAN RIGHTS WATCH, 2020)

El Comité de Derechos Económicos, Sociales y Culturales de las Naciones Unidas (CDESC), es un órgano compuesto de 18 expertos independientes que supervisa la aplicación del Pacto Internacional de Derechos Económicos, Sociales y Culturales por sus Estados partes, en el documento titulado: El derecho al disfrute del más alto nivel posible de salud (2000), ha declarado lo siguiente:

1. La salud es un derecho humano fundamental e indispensable para el ejercicio de los demás derechos humanos. Todo ser humano tiene derecho al disfrute del más alto nivel posible de salud que le permita vivir dignamente. (...)

3. El derecho a la salud está estrechamente vinculado con el ejercicio de otros derechos humanos y depende de esos derechos, que se enuncian en la Carta Internacional de Derechos, en particular el derecho a la alimentación, a la vivienda, al trabajo, a la educación, a la dignidad humana, a la vida, a la no discriminación, a la igualdad, a no ser sometido a torturas, a la vida privada, al acceso a la información y a la libertad de asociación, reunión y circulación. Esos y otros derechos y libertades abordan los componentes integrales del derecho a la salud. (ONU, 2020, párr. 1 y 3 , pp. 1 y 2)

El derecho a la salud establece que los establecimientos, bienes y servicios de salud deberían:

(1) Ser suficientes en cantidad y disponibilidad. (2) Ser accesibles y estar al alcance de todos, sin 
discriminación alguna, incluso a los sectores más vulnerables y marginados de la población y (3) Ser apropiados desde el punto de vista científico y médico, y ser de buena calidad.

Los Principios de Siracusa, adoptados por el Consejo Económico y Social de las Naciones Unidas en 1984, y las observaciones generales del Comité de Derechos Humanos de las Naciones Unidas sobre los estados de emergencia y la libertad de movimiento brindan directrices autorizadas sobre las respuestas gubernamentales que restringen los derechos humanos por razones de salud pública o emergencia nacional. Cualquier medida tomada para proteger a la población que limite los derechos y libertades de las personas debe ser legal (la restricción debe estar contemplada en la ley), necesaria (la restricción debe ser necesaria para la protección de uno de los sectores estipulados en el ICCPR) y proporcional (la restricción debe ser proporcional al interés que está en juego). Los estados de emergencia deben tener una duración limitada y cualquier reducción de los derechos debe tener en cuenta el impacto desproporcionado en poblaciones específicas o grupos marginados. (HUMAN RIGHTS WATCH, 2020; OFICINA DEL ALTO COMISIONADO DE LAS NACIONES UNIDAS, 2020b)

Un grupo de expertos en Derechos Humanos de la Organización de las Naciones Unidas (ONU), el 16 de marzo de 2020, manifestaron que:

\begin{abstract}
...las declaraciones de emergencia basadas en el brote de COVID-19 no deberían usarse como excusa para atacar a grupos, minorías o individuos particulares. No deberían utilizarse como una tapadera para acciones represivas con el pretexto de proteger la salud (...) y no deberían usarse simplemente para sofocar la disidencia. (HUMAN RIGHTS WATCH, 2020)
\end{abstract}

Los Principios de Siracusa establecen específicamente que, como mínimo, las restricciones, deben: (1) Imponerse y aplicarse de conformidad con la ley; (2) Responder a un objetivo legítimo de interés general; (3) Ser estrictamente necesarias en una sociedad democrática para alcanzar su objetivo; (4) Ser lo menos intrusivas y restrictivas posible para cumplir su objetivo; (5) Basarse en evidencia científica y no aplicarse de manera arbitraria ni discriminatoria y (6) Tener una duración limitada, ser respetuosas con la dignidad humana y estar sujetas a revisión. (HUMAN RIGHTS WATCH, 2020). 
MALAMUD y NÚÑEZ (2020) consideran que la expansión de la pandemia por América Latina va a tener una primera derivada de tipo político. Esta crisis está atacando a los gobiernos de la región en una de las áreas que se va a poner a prueba en esta crisis: los servicios públicos y el sanitario. Dado los altos índices de corrupción de algunos gobiernos, junto con el estancamiento económico, administraciones ineficientes y mal funcionamiento de los servicios públicos, provocó estallidos sociales a finales de 2019 ocasionando que Ecuador paralizara un plan de ajuste y Chile iniciara un proceso de cambio constitucional o incluso provocaron como en Bolivia la caída del gobierno.

Tabla $\mathbf{N}^{\circ} 1$ Comparativa de países con crisis gubernamental desde el punto de vista político

\begin{tabular}{|l|l|}
\hline \multicolumn{1}{|c|}{ Países } & \multicolumn{1}{c|}{ Situación política } \\
\hline CHILE & Muchos ejecutivos poseen un escaso liderazgo social. \\
\hline ARGENTINA & Afrontan una nueva crisis económica de enorme magnitud \\
\hline PERÚ Y ECUADOR & Se encuentran en el tramo final de sus mandatos \\
\hline BOLIVIA & Se enfrentan a una campaña electoral muy polarizada \\
\hline $\begin{array}{l}\text { La mayoría de los países de } \\
\text { Centroamérica y el Caribe }\end{array}$ & Cuentan con unas administraciones públicas muy débiles \\
\hline $\begin{array}{l}\text { NICARAGUA } \\
\text { VENEZUELA }\end{array}$ & Están sumidos en un fuerte deterioro institucional y económico \\
\hline HAITÍ & Considerado Estado Fallido \\
\hline MEXICO Y BRASIL & Consideradas Grandes Potencias \\
\hline
\end{tabular}

Fuente: Elaboración Propia (2020), tomado de Malamud y Núñez (2020)

Estos gobiernos tendrán que afrontar la crisis del coronavirus estando sobrecargados por unos aparatos del Estado con graves problemas de funcionamiento (mal financiados y, en algunos casos, con escaso personal, sin medios y sin formación). Pese a todo, la lejanía y el aislamiento geográfico han jugado, hasta ahora, a favor de América Latina cuyos gobiernos se han podido beneficiar de la experiencia de lo ocurrido en Asia y Europa. Esto ha facilitado a las autoridades reaccionar antes y tomar medidas drásticas con mayor antelación. (MALAMUD y NÚÑ̃EZ, 2020).

Los autores citados destacan que la pandemia del coronavirus hundió las bolsas europeas y la estadounidense (así como las asiáticas y las latinoamericanas), ocasionando el derrumbamiento de los precios de las materias primas, paralizado la expansión económica China lo que desencadenará un bajo el crecimiento económico latinoamericano, con impacto general y efectos 
moderados en América Latina. La medida de la magnitud se verá dependiendo de lo que tarde China en recuperarse, sobre todo los países más vinculados al "gigante asiático" y que dependan de su materia prima.

\section{ALGUNOS ASPECTOS SOBRE LOS DERECHOS HUMANOS Y EL COVID-19}

Las oficinas de Naciones Unidas, la Comisión Interamericana de Derechos Humanos, la Organización para la Seguridad y la Cooperación en Europa, la Organización Mundial de la Salud, la Organización Panamericana de la Salud y Access Now, insisten en la recomendación del deber de todo Estado de salvaguardar la vida de los ciudadanos con planes e intervenciones fundamentadas en el respeto a los derechos humanos y las garantías constitucionales. Michelle Bachelet, la Alta Comisionada de las Naciones Unidas para los Derechos Humanos, declaró durante el Consejo celebrado en Ginebra el 6 de marzo de 2020, expreso su preocupación con los siguientes argumentos:

Los confinamientos, las cuarentenas y otras medidas de esa índole orientadas a combatir la expansión del COVID-19 deben aplicarse siempre en la más estricta observación de las normas de derechos humanos y de manera proporcional y ponderada al riesgo en que se incurre, pero aún así pueden repercutir gravemente sobre la vida de las personas. (...)

El COVID-19 pone a prueba a nuestras sociedades y todos aprendemos y nos adaptamos a medida que respondemos al virus. Pero es preciso que la dignidad y los derechos humanos sean los pilares fundamentales de ese esfuerzo y no una consideración accesoria. (OFICINA DEL ALTO COMISIONADO DE LAS NACIONES UNIDAS, 2020a)

A continuación se presentan un breve análisis en torno a algunos Derechos Humanos afectados por las medidas implementadas por el COVID-19.

\section{-DERECHO A LA LIBERTAD.}

Cabe destacar que las cuarentenas, en particular las que afectan al derecho a la libertad y la seguridad personales, sólo son permisibles si se llevan a cabo de manera no discriminatoria y, aunque respondan, como este caso, a una necesidad pública o social apremiante, si tienen una finalidad legítima y son proporcionales a ella; deben ser de duración limitada y revisarse periódicamente, y si hay varios tipos de limitaciones posibles, debe adoptarse la menos restrictiva. (AMNISTÍA INTERNACIONAL, 2020)

Lo mismo sucede con las restricciones y prohibiciones de viaje, que también pueden afectar al derecho a la libertad de circulación. Cuando se impongan deben ser legítimas, necesarias y proporcionales, es decir, ser la menos restrictiva de las alternativas posibles, y no deben tener 
carácter discriminatorio. (AMNISTÍA INTERNACIONAL, 2020). Las medidas tomadas fueron el cierre de las fronteras y la prohibición de los vuelos nacionales e internacionales en varios países.

\section{-DERECHO A LA SALUD}

De acuerdo a recomendaciones de Amnistía Internacional (2020), los Estados deben garantizar que todas las personas y comunidades afectadas tienen acceso a una información clara, accesible, oportuna y significativa sobre la naturaleza y el grado de amenaza para la salud, a la información sobre las posibles medidas que se tomen para mitigar los riesgos, y también a la información de alerta temprana sobre las posibles consecuencias futuras y las iniciativas de respuesta en curso. Sobre este punto del Derecho al acceso a la información será tratado más adelante.

Los Estados deben garantizar que todas las personas tengan acceso a la seguridad social, incluido el reposo por enfermedad, la atención a la salud y la licencia por maternidad, si están enfermas o en cuarentena o tienen que cuidar de personas dependientes afectadas, incluido niños y niñas debido al cierre de colegios.

Los estándares internacionales sobre el derecho a la salud indican que los bienes, las instalaciones y los servicios de atención médica, incluido el acceso a la atención y las vacunas y curas desarrolladas para COVID-19, deben estar disponibles en cantidad suficiente para todas las personas, especialmente para los sectores más vulnerables o marginados de la población, que deben tener acceso a ellos sin discriminación.

Ese acceso debe ser asequible para todas las personas. Esto significa que los Estados deberían trabajar con las partes implicadas (incluidas las compañías farmacéuticas) para conseguirlo, de manera que todos los actores mantengan como prioridad la garantía de los derechos humanos. El derecho a la salud incluye tanto la salud física como la mental. Los Estados deben garantizar que el apoyo psicosocial esté disponible para posibles consecuencias de la epidemia de COVID-19 sobre salud mental y las medidas de contención posteriores, como la ansiedad o la depresión.

Algunas de las medidas aplicadas para mejorar la salud pública pueden tener consecuencias negativas en el derecho al trabajo y los derechos laborales, haciendo que las personas con trabajos precarios se vean afectadas de manera desproporcionada. Entre ellas figuran los trabajadores y trabajadoras migrantes, las personas sujetas a condiciones poco seguras o precarias de trabajo propias de la economía bajo demanda, las personas con bajos ingresos, las personas migrantes en situación administrativa irregular y las personas empleadas en el sector informal. Los Estados 
deben garantizar que todas ellas también tienen acceso a las prestaciones que ofrece la seguridad social.

Otros grupos de riesgo, que deben ser tomados en cuenta, son los trabajadores de la salud, los guardias y otros empleados de prisiones u otro personal encargado de hacer cumplir la ley que se ocupe de aplicar y hacer cumplir las medidas de salud pública, así como profesionales que no pertenecen al sector público que están trabajando para garantizar el acceso a servicios básicos, donde los Estados deben garantizar también que se establecen mecanismos en pro de su derecho a la salud como consecuencia de su exposición a COVID-19.

Los grupos vulnerables como, las personas de edad y con dolencias médicas preexistentes (como asma, diabetes o cardiopatías) parecen estar más expuestas a enfermar de gravedad por el virus y por lo tanto los Estados deben hacer lo posible por protegerlas. También Personas que viven en la pobreza y con menor acceso a medidas preventivas, incluidas mascarillas y desinfectantes; personas sin hogar que se enfrentan a desafíos importantes para el autoaislamiento; personas migrantes en situación administrativa irregular; personas con ingresos más bajos y empleo inseguro; aquellas que no tienen más remedio que vivir o trabajar cerca de otras que no tienen acceso a medidas preventivas adecuadas, como en las cárceles o en entornos laborales que presentan riesgos para la salud; o personas sin acceso adecuado a agua y saneamiento. Los Estados deben velar que puedan acceder a los mismos servicios que el resto de la población sin discriminación.

Sobre este tema de la salud, Michelle Bachelet en su declaración durante el Consejo celebrado en Ginebra el 6 de marzo de 2020 consideró que:

Para combatir eficazmente la epidemia, es preciso velar por que todos tengan acceso al tratamiento y que no se niegue a nadie la atención sanitaria por motivos económicos o a causa de la estigmatización. (OFICINA DEL ALTO COMISIONADO DE LAS NACIONES UNIDAS, 2020a)

En un comunicado de prensa, la Comisión Interamericana de Derechos Humanos (CIDH) y su Relatoría Especial sobre Derechos Económicos, Sociales, Culturales y Ambientales (REDESCA) reconocen la complejidad que enfrentan los Estados y las sociedades del hemisferio debido a las medidas excepcionales que requiere la pandemia global ocasionada por el coronavirus COVID-19 que avanza en forma exponencial. Recuerdan a los Estados que el derecho a la salud se debe garantizar a todas las personas dentro de su jurisdicción, sin ningún tipo de discriminación, de conformidad con los estándares e instrumentos interamericanos e internacionales de derechos humanos y que los Estados deben tomar como prioridad la integridad y bienestar de las personas 
profesionales de la salud frente a la pandemia. (COMISIÓN INTERAMERICANA DE DERECHOS HUMANOS (CIDH), 2020).

\section{-DERECHOS DE LOS MIGRANTES Y PERSONAS MARGINADAS}

La Red de las Naciones Unidas sobre Migración sugiere a los Estados proteger a los migrantes, por lo tanto las restricciones de movilidad durante las cuarentenas y las restricciones de desplazamientos no deben afectar "indebidamente" los derechos humanos de los migrantes y la posibilidad que tiene de "solicitar asilo". Para CHIRINOS (2020), en su artículo de prensa señala:

Las medidas deben incluir prevención, pruebas y tratamientos adecuados, acceso continuo y aumentado a refugios de emergencia para personas sin hogar sin barreras relacionadas con el estado migratorio; y suspensiones de desalojos. Los expertos insisten en que es particularmente importante que las autoridades hagan todo lo posible para enfrentar la xenofobia, incluso cuando los migrantes y otras personas están sujetas a discriminación o violencia relacionada con el origen y la propagación de la pandemia. (CHIRINOS, 2020, s/p)

Los gobiernos deberían garantizar que se proporcionen todos los servicios de salud relacionados con el COVID-19, acceder a las pruebas, la atención medica preventiva y el tratamiento, sin estigma ni discriminación de ningún tipo, incluso por motivos de orientación sexual e identidad de género, (LGBTQ+), este grupo en particular enfrentan discriminación para acceder a la atención médica, según informes de casos documentados por Human Rights Watch en países como EE.UU., Tanzania, Japón, Indonesia, Bangladesh, Rusia y el Líbano. En el caso de los inmigrantes indocumentados, los gobiernos deben tomar medidas para asegurar a las poblaciones vulnerables que no corren riesgo de represalias ni de ser deportados si acceden a cuidados vitales.

Los gobiernos tienen la obligación de garantizar que, ante una grave crisis de salud pública, no se convierta en una crisis de derechos humanos porque las personas no puedan acceder a una atención médica adecuada, para evitar esto los gobiernos deberían tomar medidas para garantizar que todas las personas tengan opciones de tratamiento y atención médica asequible y accesible.

La directora para las Américas de Amnistía Internacional, Erika Guevara Rosas, ante la crisis sobre las condiciones migratorias, señaló que:

La condición migratoria es irrelevante para la dignidad y el derecho a vivir de todos los seres humanos. En lugar de incrementar los riesgos para la salud de la población, los gobiernos deberían hacer todo lo que puedan para protegerla. Indicó además que: Para combatir con eficacia el coronavirus, COVID-19, en las Américas e impedir 
miles de muertes evitables, los Estados deben liberar rápidamente a las personas en detención migratoria, (...) y garantizar que tengan acceso, sin discriminación, a atención médica para salvar sus vidas. (AMNISTÍA INTERNACIONAL, 2020).

Las autoridades de varios países del continente americano, entre ellos, Canadá, Estados Unidos, México, Curazao y Trinidad y Tobago detienen de forma peligrosa y discriminatoria a migrantes y solicitantes de asilo, basándose únicamente en la situación migratoria de esas personas, afirmó hoy Amnistía Internacional. Al hacerlo, empujan a muchas personas a entornos inseguros y poco higiénicos, contrario a las pautas internacionales de derechos humanos y salud pública. (Amnistía Internacional, 2020).

Tabla $\mathrm{N}^{0} 2$ Comparativa de países con ejemplos de casos sobre situaciones de DDHH en relación a Derechos de los migrantes.

\begin{tabular}{|c|c|c|}
\hline Países & Situaciones & $\begin{array}{l}\text { Recomendaciones de Amnistía } \\
\text { Internacional }\end{array}$ \\
\hline CANADÁ & $\begin{array}{l}\text { La Agencia de Servicios Fronterizos de } \\
\text { Canadá tiene en sus centros de detención } \\
\text { migratoria a algunos cientos de personas } \\
\text { con altas tasas de mortalidad. } \\
\text { Las personas detenidas y sus familias } \\
\text { afrontan un estrés psicológico sustancial, } \\
\text { han estado sometidas a tanta angustia por } \\
\text { el riesgo de contraer el COVID-19 } \\
\text { mientras están detenidas que han iniciado } \\
\text { una huelga de hambre para pedir ser } \\
\text { liberadas. }\end{array}$ & $\begin{array}{l}\text { Amnistía Internacional recomendó } \\
\text { reducir rápidamente al mínimo el } \\
\text { número de personas en centros de } \\
\text { detención migratoria }\end{array}$ \\
\hline CURAZAO & $\begin{array}{l}\text { Las autoridades de Curazao detienen con } \\
\text { frecuencia a migrantes y solicitantes de } \\
\text { asilo procedentes de Venezuela, } \\
\text { negándoles el acceso a la protección } \\
\text { internacional. } \\
\text { En marzo de 2020, la Plataforma } \\
\text { Regional de Coordinación Interagencial } \\
\text { estimó que había } 16.500 \text { personas } \\
\text { venezolanas en la isla, pero se desconocía } \\
\text { cuántas de ellas estaban en detención } \\
\text { migratoria. } \\
\text { Bajo detención Migratoria se han } \\
\text { evidenciado pésimas condiciones, } \\
\text { hacinamiento, abusos sexuales, falta de } \\
\text { higiene y camas inadecuadas en las zonas } \\
\text { en las que estaban detenidas personas en } \\
\text { situación migratoria irregular. }\end{array}$ & $\begin{array}{l}\text { Curazao debe liberar a todas las } \\
\text { personas migrantes y solicitantes de } \\
\text { asilo que se encuentran detenidas por } \\
\text { su condición migratoria y otorgarles } \\
\text { acceso a la atención de salud que } \\
\text { requieran y a otros servicios } \\
\text { esenciales. }\end{array}$ \\
\hline MÉXICO & $\begin{array}{l}\text { Tras el cierre de la frontera las } \\
\text { autoridades han fallado en no considerar } \\
\text { alternativas a la detención para las } \\
\text { personas migrantes que están actualmente }\end{array}$ & $\begin{array}{l}\text { México debe poner rápidamente en } \\
\text { libertad a todas las personas } \\
\text { migrantes y solicitantes de asilo que } \\
\text { pueda de las que actualmente se }\end{array}$ \\
\hline
\end{tabular}




\begin{tabular}{|c|c|c|}
\hline & $\begin{array}{l}\text { detenidas, dada la imposibilidad de ser } \\
\text { liberadas vía la deportación en autobús a } \\
\text { Centroamérica. } \\
\text { Se ha reportado que algunos centros de } \\
\text { detención migratoria están superpoblados } \\
\text { e incluso mezclan a niños y adolescentes } \\
\text { con poblaciones adultas debido a la falta } \\
\text { de espacio. } \\
\text { En marzo } 2020 \text { se reportaron protestas en } \\
\text { los centros de detención migratoria. } \\
\text { Las autoridades mexicanas podrían no } \\
\text { respetar su propia legislación migratoria } \\
\text { al permitir un régimen de detención } \\
\text { indefinida, lo cual incumpliría los } \\
\text { estándares internacionales de derechos } \\
\text { humanos. }\end{array}$ & $\begin{array}{l}\text { encuentran en centros de detención } \\
\text { migratoria; la salud mental y física de } \\
\text { esas personas no se puede preservar } \\
\text { en esos centros. } \\
\text { Las autoridades mexicanas no solo } \\
\text { deben liberarlas, sino también } \\
\text { brindarles protección humanitaria de } \\
\text { emergencia para garantizar que todas } \\
\text { ellas tengan acceso sin discriminación } \\
\text { a servicios esenciales, cuidados y } \\
\text { seguridad, incluidas una alimentación } \\
\text { y una atención de salud adecuadas. }\end{array}$ \\
\hline $\begin{array}{l}\text { TRINIDAD } \\
\text { Y } \\
\text { TOBAGO }\end{array}$ & $\begin{array}{l}\text { No cuenta con una legislación nacional } \\
\text { sobre personas refugiadas } \\
\text { El país sigue criminalizando y deteniendo } \\
\text { a personas migrantes y refugiadas } \\
\text { (especialmente aquellas que huyen de la } \\
\text { crisis en Venezuela) que ingresan en su } \\
\text { territorio de manera irregular. Eso es } \\
\text { contrario a los estándares internacionales } \\
\text { de derechos humanos. } \\
\text { Amnistía Internacional no ha podido } \\
\text { visitar el Centro de Detención Migratoria. } \\
\text { Tampoco se les otorga acceso a otras } \\
\text { organizaciones no gubernamentales y de } \\
\text { derechos humanos }\end{array}$ & $\begin{array}{l}\text { El gobierno de Trinidad y Tobago } \\
\text { debe liberar a todas las personas } \\
\text { migrantes y solicitantes de asilo que } \\
\text { se encuentran en detención migratoria } \\
\text { simplemente por ingresar al país de } \\
\text { manera irregular o que esperan que se } \\
\text { resuelvan sus solicitudes de asilo y } \\
\text { darles acceso a la atención de salud } \\
\text { que requieran y a otros servicios } \\
\text { esenciales, sin discriminación. }\end{array}$ \\
\hline $\begin{array}{l}\text { ESTADOS } \\
\text { UNIDOS }\end{array}$ & $\begin{array}{l}\text { El Servicio de Inmigración y Control de } \\
\text { Aduanas del Departamento de Seguridad } \\
\text { Nacional de Estados Unidos refirió un } \\
\text { primer caso confirmado de COVID-19 en } \\
\text { instalaciones de detención migratoria. } \\
\text { Amnistía Internacional ha recibido } \\
\text { testimonios perturbadores de personas } \\
\text { detenidas sobre condiciones peligrosas en } \\
\text { centros de detención migratoria del ICE, } \\
\text { que ponen a quienes tienen problemas } \\
\text { médicos preexistentes en mayor peligro } \\
\text { de contraer el COVID-19 y de morir } \\
\text { como consecuencia del virus. }\end{array}$ & $\begin{array}{l}\text { Amnistía Internacional emitirá un } \\
\text { informe documentando como } \\
\text { oficiales del DHS y los centros del } \\
\text { ICE no han adoptado medidas } \\
\text { adecuadas para garantizar la salud } \\
\text { pública (por ejemplo, suministrando } \\
\text { jabón y gel desinfectante a las } \\
\text { personas detenidas, facilitando el } \\
\text { distanciamiento social según } \\
\text { estándares internacionales y } \\
\text { brindando servicios de salud } \\
\text { adecuados y receptivos a quienes } \\
\text { presenten síntomas de COVID-19). }\end{array}$ \\
\hline
\end{tabular}

Fuente: Elaboración propia (2020).

\section{EL ACCESO A LA INFORMACIÓN}


Según el derecho internacional de los derechos humanos, los gobiernos tienen la obligación de proteger el derecho a la libertad de expresión, incluido el derecho a buscar, recibir y difundir información de todo tipo, independientemente de las fronteras. Po lo tanto, los gobiernos son responsables de proporcionar la información necesaria para la protección y promoción de los derechos, incluido el derecho a la salud. Las restricciones permisibles a la libertad de expresión por razones de salud pública, mencionadas anteriormente, no pueden poner en peligro el derecho propiamente dicho. (HUMAN RIGHTS WATCH, 2020)

El Comité de Derechos Económicos, Sociales y Culturales considera como una “obligación de prioridad" proporcionar "educación y acceso a la información relativa a los principales problemas de salud en la comunidad, con inclusión de los métodos para prevenir y combatir esas enfermedades". (HUMAN RIGHTS WATCH, 2020, s/p). Una respuesta al COVID-19 respetuosa con los derechos humanos debe garantizar la disponibilidad y la accesibilidad universal de información precisa y actualizada sobre el virus.

El acceso a la información pública también debe ser prioridad en este contexto de pandemia. CHIRINOS (2020), destaca que:

Recomiendan a los funcionarios públicos garantizar la difusión de información oportuna y transparente, técnicamente correcta y basada en evidencias. El público tiene derecho a la información que puede afectar su salud y la de sus allegados, establece la Organización Mundial de la Salud. La Organización Panamericana de la Salud, además, considera indispensable proporcionar información epidemiológica para realizar una evaluación de riesgos a nivel nacional, regional y global. (CHIRINOS, 2020, s/p)

En el mismo orden de ideas, los garantes para la libertad de expresión y la libertad de los medios de comunicación de las Naciones Unidas, la Comisión Interamericana de Derechos Humanos y el Representante para la Libertad de los Medios de Comunicación de la Organización para la Seguridad y la Cooperación en Europa emitieron una declaración conjunta, en la que instaban a los Estados a garantizar la Libertad de Expresión, en los siguientes términos:

Primero, es esencial que los gobiernos proporcionen información veraz sobre la naturaleza de la amenaza que supone el coronavirus. Los gobiernos de todo el mundo están obligados, en virtud de las normas de los derechos humanos, a proporcionar información fidedigna en formatos accesibles a todos, prestando especial atención a garantizar el acceso a la información por parte de las personas con acceso limitado a Internet o a aquellas personas en condición de discapacidad a las cuales se les dificulte el acceso.

Segundo, el acceso a Internet es crítico en un momento de crisis. Es esencial que los gobiernos se abstengan de bloquear el acceso a Internet; en las situaciones en que se ha bloqueado el acceso a Internet, los gobiernos deben, con carácter prioritario, garantizar el acceso inmediato al servicio de Internet más rápido y amplio posible. Especialmente en un momento de emergencia, cuando el acceso a la información es 
de vital importancia, no se puede justificar la imposición de amplias restricciones al acceso a Internet por motivos de orden público o seguridad nacional.

Tercero, el derecho de acceso a la información significa que los gobiernos deben hacer esfuerzos excepcionales para proteger el trabajo de los periodistas. El periodismo cumple una función crucial en un momento de emergencia de salud pública, en particular cuando tiene por objeto informar al público sobre información crítica y monitorear las acciones del gobierno. Instamos a todos los gobiernos a que apliquen firmemente sus leyes de acceso a la información para garantizar que todas las personas, especialmente los periodistas, tengan acceso a la misma.

Cuarto, compartimos la preocupación de que la información falsa sobre la pandemia podría provocar preocupaciones en materia de salud, pánico y desorden. En este sentido, es esencial que los gobiernos y las empresas de Internet aborden la desinformación por sí mismos en primer lugar proporcionando información fiable. Esto puede hacerse en forma de mensajes públicos sólidos, apoyo a los anuncios de servicio público y apoyo de emergencia a la radiodifusión pública y al periodismo local (por ejemplo, mediante anuncios de salud del gobierno). Con respecto a otras medidas, como la reducción de contenidos y la censura, puede dar lugar a la limitación del acceso a información importante para la salud pública y sólo debe realizarse cuando se cumplan las normas de necesidad y proporcionalidad. Cualquier intento de penalizar la información relativa a la pandemia puede crear desconfianza en la información institucional, retrasar el acceso a información fiable y tener un efecto silenciador en la libertad de expresión.

Quinto, somos conscientes del creciente uso de herramientas de tecnología de vigilancia para rastrear la propagación del coronavirus. Si bien comprendemos y apoyamos la necesidad de realizar esfuerzos activos para hacer frente a la pandemia, también es crucial que el uso de dichas herramientas sea limitado, tanto en términos de propósito como de tiempo, y que se protejan rigurosamente los derechos individuales a la privacidad, la no discriminación, la protección de las fuentes periodísticas y otras libertades. Los Estados también deben proteger la información personal de los pacientes. Instamos encarecidamente a que todo uso de esa tecnología se atenga a las más estrictas protecciones y que sólo esté disponible de acuerdo a la legislación nacional que sea compatible con las normas internacionales de derechos humanos. (ONU, RELATORIA ESPECIAL PARA LA LIBERTAD DE EXPRESIÓN, 2020, s/p)

Al tomar medidas contra periodistas y trabajadores de la salud, algunos gobiernos no han cumplido con su obligación de proteger el derecho a la libertad de expresión. Esta situación limitó la comunicación efectiva sobre el inicio de la enfermedad y socavó la confianza en las acciones del gobierno y ponen en peligro la eficacia de la respuesta en materia de salud pública, menoscabando el derecho a acceder a información sobre la salud. (AMNISTÍA INTERNACIONAL, 2020). En este mismo orden de ideas, la Alta Comisionada, Michelle Bachelet, en otra intervención, informó que "Las autoridades nunca deberían sancionar a los profesionales de la medicina porque estos señalen las deficiencias de que adolece la respuesta a la crisis". (CHIRINOS, 2020, s/p).

Tabla $\mathbf{N}^{0} 3$ Comparativa de países con ejemplos de casos sobre situaciones de DDHH en relación a los Derechos del Acceso a la Información y la Libertad de Expresión. 


\begin{tabular}{|c|c|}
\hline País & Situación \\
\hline China & $\begin{array}{l}\text { Inicialmente retuvo información básica sobre el coronavirus del público. } \\
\text { Se detuvieron a personas por informar sobre la epidemia en las redes sociales y a } \\
\text { usuarios de Internet por "propagar rumores", censuraron conversaciones en línea } \\
\text { sobre la epidemia y restringieron los informes de los medios de comunicación. } \\
\text { Caso: la policía detuvo a Li Wenliang, médico de un hospital de Wuhan donde se } \\
\text { estaba tratando a pacientes infectados, por "difundir rumores" después de advertir } \\
\text { acerca del nuevo virus en una aplicación de chat en línea. El medico murió a } \\
\text { principios de febrero a causa del virus COVID-19. }\end{array}$ \\
\hline Irán & $\begin{array}{l}\text { El brote surgió después de que las autoridades dañaran severamente la confianza } \\
\text { pública al reprimir brutalmente las protestas antigubernamentales generalizadas. } \\
\text { La tasa inusualmente alta de casos reportados así como la inconsistencia en las cifras } \\
\text { anunciadas por funcionarios y fuentes de medios nacionales, han aumentado las } \\
\text { preocupaciones de que los datos estén siendo deliberadamente manipulados o de que } \\
\text { se estén recopilando y analizando inadecuadamente }\end{array}$ \\
\hline Tailandia & $\begin{array}{l}\text { Informantes en el sector de la salud pública y periodistas en línea se han enfrentado } \\
\text { a demandas, represalias y actos de intimidación por parte de las autoridades. } \\
\text { Denunciaron casos de presunta corrupción relacionada con el acaparamiento y la } \\
\text { especulación de mascarillas quirúrgicas y otros suministros } \\
\text { Algunos miembros del personal médico fueron amenazados con medidas } \\
\text { disciplinarias, incluida la terminación de sus contratos de trabajo y la revocación de } \\
\text { sus licencias, por denunciar la grave escasez de suministros esenciales en los } \\
\text { hospitales de todo el país. }\end{array}$ \\
\hline Rusia & $\begin{array}{l}\text { Caso: Arresto violento y la continuidad de la detención de la doctora rusa Anastasia } \\
\text { Vasilyeva, líder de un sindicato de profesionales médicos que denunció debilidades } \\
\text { en la preparación del sistema de salud para luchar contra el coronavirus, COVID- } \\
19 \text {. }\end{array}$ \\
\hline
\end{tabular}

Fuente: Elaboración propia (2020).

Otros países como Taiwán, Singapur, Corea del Sur e Italia, si priorizaron la comunicación abierta y la presentación de información transparente sobre la situación de emergencia y el número de casos del COVID-19, a saber:

Tabla $\mathbf{N}^{\circ} 4$ Comparativa de países que priorizaron la comunicación abierta.

\begin{tabular}{|l|l|}
\hline \multicolumn{1}{|c|}{ País } & \multicolumn{1}{c|}{ Medidas en pro del Derecho a la Comunicación } \\
\hline Taiwán & $\begin{array}{l}\text { Adoptó medidas inmediatas para combatir el virus, incluida la rápida difusión de } \\
\text { información fidedigna al público. }\end{array}$ \\
\hline
\end{tabular}




\begin{tabular}{|l|l|}
\hline & $\begin{array}{l}\text { Los comunicados de prensa diarios de los funcionarios de salud y los anuncios de } \\
\text { servicio público apuntan a contrarrestar la información errónea y han ayudado a } \\
\text { calmar el pánico, restaurar la confianza del público y alentar la asistencia de las } \\
\text { personas durante la crisis. }\end{array}$ \\
\hline Singapur & $\begin{array}{l}\text { Publicó y actualizó periódicamente estadísticas detalladas sobre el número y la } \\
\text { tasa de infecciones y recuperaciones }\end{array}$ \\
\hline $\begin{array}{l}\text { Corea } \\
\text { Sur }\end{array}$ & $\begin{array}{l}\text { Publicó datos de salud y los funcionarios emitían dos comunicados diarios para } \\
\text { establecer la confianza del público y promover la vigilancia ciudadana. }\end{array}$ \\
\hline Italia & $\begin{array}{l}\text { El gobierno ha celebrado conferencias de prensa diarias para compartir datos y ha } \\
\text { implementado una agresiva campaña pública sobre mejores prácticas para que las } \\
\text { personas se protejan a sí mismas y a otras de la propagación del virus. }\end{array}$ \\
\hline
\end{tabular}

Fuente: Elaboración propia (2020).

Para AMNISTÍA INTERNACIONAL (2020), la tecnología puede y debe desempeñar importantes funciones durante esta pandemia del COVID-19, como difundir mensajes de salud pública y aumentar el acceso a los servicios de salud. Lamentablemente, el aumento de los poderes de vigilancia digital de los Estados (el acceso a los datos de localización de teléfonos móviles) amenaza la privacidad, la libertad de expresión y la libertad de asociación de tal forma que podría violar derechos y minimizar la confianza en las autoridades públicas, con el consiguiente menoscabo de la eficacia de las repuestas de salud pública. Tales medidas entrañan además un riesgo de discriminación que pueden perjudicar a comunidades ya marginadas.

En esta situación de pandemia, el derecho de los derechos humanos, sigue siendo aplicable. De hecho, el marco de los derechos humanos tiene por objeto garantizar el equilibrio de los distintos derechos para proteger a las personas y las sociedades. Por lo tanto, los Estados no pueden excusarse de desatender el derecho a la privacidad y la libertad de expresión con el pretexto de gestionar una crisis de salud pública. Al contrario, la protección de los derechos humanos también promueve la salud pública. Es indiscutible que los gobiernos deben garantizar que toda restricción de estos derechos se ajuste a salvaguardar los derechos humanos. (AMNISTÍA INTERNACIONAL, 2020)

\section{-DERECHO DE ACCESO AL AGUA Y AL SANEAMIENTO}

Los derechos al agua y el saneamiento son parte del derecho a un nivel de vida adecuado. El Comité de Derechos Económicos, Sociales y Culturales de la ONU ha reafirmado que los derechos 
al agua y el saneamiento son un componente esencial del derecho a un nivel de vida adecuado y "relacionados integralmente, entre otros derechos del Pacto, con el derecho a la salud". (HUMAN RIGHTS WATCH, 2020)

Como ha señalado la OMS, la provisión de agua potable, el saneamiento y las condiciones higiénicas son esenciales para proteger la salud durante el brote de COVID-19. La prevención de la transmisión de persona a persona del coronavirus puede respaldarse en la promoción de los derechos al agua y el saneamiento, y en el apoyo a la infraestructura y los técnicos de agua y aguas residuales para garantizar la aplicación de prácticas de agua, saneamiento e higiene de manera consistente y correcta en comunidades, hogares, escuelas, mercados e instalaciones sanitarias. (HUMAN RIGHTS WATCH, 2020)

Miles de millones de personas en todo el mundo no tienen acceso a agua potable. La escasez de agua potable y saneamiento en el hogar, la escuela o en entornos de atención médica dificultará la adopción de medidas preventivas. En algunos casos, sin agua ni saneamiento adecuado, estos entornos en sí mismos pueden ser un lugar para la propagación de la enfermedad. (HUMAN RIGHTS WATCH, 2020)

En el caso particular de Venezuela, la infraestructura de atención médica es tan débil que la recomendación más básica, el lavado de manos, es difícil incluso para los proveedores de atención médica, quienes trabajan en condiciones precarias. Human Rights Watch realizó una entrevista a un grupo de médicos y enfermeras venezolanos quienes indicaron que en los últimos meses el jabón y los desinfectantes eran prácticamente inexistentes en sus clínicas y hospitales. La inflación ha aumentado y los salarios se han devaluado, lo que impiden que puedan traer sus propios suministros. Los hospitales públicos en Caracas sufren escasez habitual de agua; en hospitales remotos, la insuficiencia ha durado semanas e incluso meses. Se ha pedido que los pacientes y el personal traigan su propia agua para beber e incluso para limpiar los baños. (HUMAN RIGHTS WATCH, 2020).

Los Relatores Especiales y los Expertos Independientes forman parte de lo que se conoce como los Procedimientos Especiales del Consejo de Derechos Humanos. Procedimientos Especiales, el órgano más grande de expertos independientes del sistema de derechos humanos de las Naciones Unidas, estos expertos de la ONU, ante el tema del agua, en un comunicado emitido en Ginebra, el 23 de marzo de 2020, han destacado lo siguiente:

Dado que lavarse las manos con jabón y agua limpia es vital en la lucha contra el COVID-19, los gobiernos de todo el mundo deben proporcionar un acceso continuo a suficiente agua a las poblaciones que viven en las condiciones más vulnerables, dijo un grupo de expertos y expertas de la ONU. 
La lucha mundial contra la pandemia tiene pocas posibilidades de éxito si la higiene personal, la principal medida para prevenir el contagio, no está al alcance de los 2.200 millones de personas que no tienen acceso a servicios de agua potable", dijeron los expertos.

Pedimos a los gobiernos que prohíban de inmediato los cortes de agua a quienes no puedan pagar las facturas de agua. También es esencial que proporcionen agua de manera gratuita mientras dure la crisis a las personas que viven en la pobreza y a las afectadas por las dificultades económicas que se avecinan. Se debe obligar a los proveedores tanto públicos como privados a cumplir estas medidas fundamentales. Para las personas más privilegiadas, lavarse las manos con jabón y agua limpia - la principal defensa contra el virus - es un gesto sencillo. Pero para algunos grupos en todo el mundo es un lujo que no pueden permitirse. (OFICINA DEL ALTO COMISIONADO PARA LAS NACIONES UNIDAS, 2020c, s/p)

\section{MEDIDAS O PLANES DE EMERGENCIA QUE HAN APLICADO LOS ESTADOS CON MOTIVO DEL COVID-19}

A continuación para presentar este punto, se va a hacer una breve descripción de las medidas o planes de emergencia que han implementado algunos países de América Latina en la Tabla Nº4.

Tabla N$^{\circ} 5$ Comparativa de Venezuela y Centro América con sus Planes de Emergencia ante el COVID-19

\begin{tabular}{|c|c|}
\hline País & Plan de Emergencia \\
\hline Venezuela & $\begin{array}{l}\text {-Se decretó la Cuarentena social voluntaria, el Estado de Alarma y el cierre de } \\
\text { restaurantes y tiendas no alimentarias. (ALGARRA, 2020) } \\
\text {-Suspensión durante seis meses del pago de arrendamiento de inmuebles de uso } \\
\text { comercial y de aquellos utilizados como vivienda principal y la prohibición de los } \\
\text { desalojos forzosos. } \\
\text {-Inamovilidad laboral hasta el } 31 \text { de diciembre de este año. Se activó un plan } \\
\text { especial del pago de nóminas a través del sistema patria por un lapso de seis meses; } \\
\text { suspensión de pago moratorio de intereses de crédito. Suspendió el pago de interés } \\
\text { de pago de capital a todos los créditos otorgados por los bancos, aunque desde hace } \\
\text { meses la banca no otorga créditos; } \\
\text {-Prohibió,, durante los próximos seis meses, el corte de servicios de } \\
\text { telecomunicaciones y de servicios públicos. (NATERA, 2020). } \\
\text {-Ministerio de Finanzas y Sudeban dictaron normas para favorecer a todos los } \\
\text { sectores productivos; Se aprueba la suspensión de pagos de capital e intereses de } \\
\text { todos los créditos del país por un lapso de } 6 \text { meses. } \\
\text {-Se aprobó la exoneración de tributos y pago de cualquier arancel a la importación } \\
\text { de materia prima, bienes de capital e insumos. } \\
\text { - Se coordinó con empresas de telecomunicaciones para mejorar, ampliar y } \\
\text { garantizar los servicios durante esta coyuntura y la prohibición, en los próximos } \\
\text { seis meses, del corte de servicios de telecomunicaciones, televisión por cable, } \\
\text { telefonía o cualquier medio de comunicación familiar. (VIERA, 2020) }\end{array}$ \\
\hline Costa Rica & $\begin{array}{l}\text {-Gobierno anunció excepciones a la restricción vehicular. Y aumento de multas y } \\
\text { sanciones por violación a la restricción vehicular durante emergencia por COVID- } \\
19 \\
\text {-Cierre temporal de establecimientos clasificados como sitios de reunión pública. }\end{array}$ \\
\hline
\end{tabular}




\begin{tabular}{|c|c|}
\hline & $\begin{array}{l}\text {-Imposición de multas para quien violente ordenes sanitarias de aislamiento } \\
\text {-Ley de Alivia Fiscal ante el COVID-19: Contiene una moratoria sobre el Impuesto } \\
\text { sobre el Valor Agregado, Impuesto Selectivo de Consumo y aranceles, durante los } \\
\text { meses de abril, mayo y junio. Asimismo, contiene una dispensa del pago parcial } \\
\text { del Impuesto sobre las Utilidades para los meses de abril, mayo y junio, así como } \\
\text { una exoneración del Impuesto sobre el Valor Agregado para alquileres } \\
\text { comerciales. Conceden moratoria de cuatro meses en pago de impuestos turísticos } \\
\text {-Reducción temporal de jornadas de trabajo y medidas laborales en sector público } \\
\text { para combatir el COVID-19: se dispondrá la permanencia de un máximo de } 20 \% \\
\text { de funcionarios en las instituciones, así como una abstención en el aumento salarial } \\
\text { (SAYAGUÉS, 2020) }\end{array}$ \\
\hline Pa & $\begin{array}{l}\text {-Ley general sobre medidas de emergencia para afrontar la crisis sanitaria causada } \\
\text { por la pandemia del COVID-19: con el fin de adoptar temporalmente medidas de } \\
\text { emergencia para proteger la vida de las personas, bienes y el patrimonio nacional } \\
\text { ante el grave riesgo colectivo que representa la crisis sanitaria ocasionada por la } \\
\text { pandemia del COVID-19. } \\
\text {-Servicio Nacional de Migración extiende vigencia de permisos de residencia de } \\
\text { extranjeros ante la situación de emergencia en Panamá y extienden la vigencia de } \\
\text { los permisos de trabajos emitidos a trabajadores extranjeros ante la situación de } \\
\text { emergencia en Panamá por el COVID-19. } \\
\text {-Gobierno adopta medidas tributarias para aliviar el impacto económico producto } \\
\text { del Estado de Emergencia Nacional, concede un plazo para el pago de tributos } \\
\text { que se causen o deban pagarse durante dicho periodo sin que ello conlleve el pago } \\
\text { de intereses, recargos y multas y extiende prórroga para la presentación y pago de } \\
\text { tributos } \\
\text {-Ministerio de Salud adopta medidas de movilidad ciudadana para mitigar la } \\
\text { propagación de la pandemia de COVID-19 e implementa el Toque de Queda. } \\
\text {-Aprobó Ley con medidas sociales especiales que suspenden temporalmente el } \\
\text { pago de servicios públicos en atención al estado de emergencia nacional } \\
\text {-Autoridad Nacional de Aduanas estableció la implementación de un } \\
\text { procedimiento temporal para la importación de mercancía bajo modalidad especial } \\
\text { de envío de socorro (ayuda y asistencia humanitaria). (SAYAGUÉS, 2020) }\end{array}$ \\
\hline Guaten & $\begin{array}{l}\text {-Guatemala emite Ley de Emergencia para Proteger a los Guatemaltecos de los } \\
\text { efectos causados por la Pandemia Coronavirus COVID-19. Vigilará que no se } \\
\text { produzca acaparamiento; el personal del Estado debe estar disponible al llamado } \\
\text { oficial con el objeto de permitir el correcto funcionamiento de las instituciones, y } \\
\text { en consecuencia los servicios públicos; de igual forma se facilitará la contratación } \\
\text { del personal técnico y profesional; Se prohíbe el cobro de multas, moras, gastos } \\
\text { administrados o intereses, generados por atrasos en pago de cuotas } \\
\text { correspondientes a centros educativos o de universidades; asimismo, los } \\
\text { estudiantes no estarán sujetos a expulsión u otras sanciones; } \\
\text {-También se menciona la espera de las obligaciones crediticias, otorgando } \\
\text { diferimientos de hasta } 6 \text { meses sin intereses moratorios, también para las personas } \\
\text { que suscribieron convenios de pago } \\
\text {-Gobierno declara toque de queda y dicta medidas adicionales que deben tomarse } \\
\text { en cuenta durante el Estado de Calamidad } \\
\text {-Continuidad de servicios básicos y prohibición de corte de estos servicios: } \\
\text { Prohibir el corte de servicios de energía eléctrica, agua, teléfono e internet, por } \\
\text { pagos atrasados. }\end{array}$ \\
\hline
\end{tabular}




\begin{tabular}{|c|c|}
\hline & $\begin{array}{l}\text { Congreso conoce de iniciativa para apoyar personas y familias que se vean } \\
\text { ectadas económicamente por el COVID-19. (SAYAGUÉS, 2020) }\end{array}$ \\
\hline $\begin{array}{l}\text { República } \\
\text { Dominicana }\end{array}$ & $\begin{array}{l}\text {-Gobierno de la República Dominica decreta medias de aislamiento y Toque de } \\
\text { Queda. } \\
\text {-Se otorgan beneficios del Fondo de Asistencia Solidaria al Empleado (FASE): La } \\
\text { Presidencia de la República, el Ministerio de Hacienda y el Ministerio de Trabajo } \\
\text { publicaron los pasos y requisitos para acogerse al Fondo de Asistencia Solidaria al } \\
\text { Empleado (FASE), un programa administrado por el Estado para apoyar a los } \\
\text { trabajadores formales suspendidos debido a los efectos del COVID-19 con una } \\
\text { transferencia monetaria a través de sus empresas. } \\
\text {-Dirección General de Impuestos Internos establece medidas complementarias en } \\
\text { relación al virus COVID-19: Aplazamiento de acuerdos de pago; Exención del } \\
\text { pago de anticipos del Impuesto sobre la Renta (ISR). } \\
\text {-Superintendencia de Electricidad emite instrucción sobre no suspensión de } \\
\text { suministro eléctrico por falta de pago. (SAYAGUÉS, 2020) }\end{array}$ \\
\hline EI Sa & $\begin{array}{l}\text {-Se decretan medidas extraordinarias de prevención y contención para declarar el } \\
\text { territorio nacional como zona sujeta a control sanitario, a fin de contener la } \\
\text { pandemia COVID-19: indica quienes son las personas autorizadas para circular en } \\
\text { el período de cuarentena. } \\
\text {-Dirección General de Impuestos Internos comunica que declaraciones e informes } \\
\text { deberán presentarse en línea: los plazos para la presentación de las declaraciones } \\
\text { e informes tributarios no han sido modificados, por lo que se mantienen los } \\
\text { establecidos en el calendario, Código Tributario y Leyes correspondientes. } \\
\text {-Otorga beneficios fiscales relacionados con la contribución especial de turismo, } \\
\text { el Impuesto sobre la Renta del ejercicio impositivo } 2019 \text { y el Pago o Anticipo a } \\
\text { Cuenta de Impuesto sobre la Renta. } \\
\text {-Se decreta: Suspensión del pago de la cuota de energía eléctrica por } 3 \text { meses; } \\
\text { Suspensión del pago de la cuota de agua por } 3 \text { meses; Congelamiento del cobro de } \\
\text { créditos hipotecarios, personales, tarjetas de crédito; Suspensión por } 3 \text { meses del } \\
\text { pago de la cuota de teléfono, cable e internet; Suspensión por } 3 \text { meses de las cuotas } \\
\text { de arrendamiento de los inmuebles. } \\
\text {-Restringe temporalmente derechos constitucionales para atender la Pandemia } \\
\text { COVID-19: La restricción a la libertad de tránsito; Respecto a la restricción al } \\
\text { derecho de los habitantes a reunirse pacíficamente y sin armas, podrán prohibirse } \\
\text { las reuniones de habitantes, salvo que las mismas tengan fines religiosos, } \\
\text { culturales, económicos o deportivos, autorizadas previamente por dichas } \\
\text { autoridades, pero se limita las aglomeraciones de más de } 50 \text { personas. } \\
\text {-No se restringe la libertad de expresión, la libertad de difusión del pensamiento, } \\
\text { el derecho de asociación, la inviolabilidad de la correspondencia, ni la interferencia } \\
\text { o intervención de las telecomunicaciones, así como ningún otro derecho o libertad } \\
\text { fundamental no comprendido en el Decreto. (SAYAGUÉS, 2020) }\end{array}$ \\
\hline Honduras & $\begin{array}{l}\text {-Gobierno anuncia medidas adicionales para afrontar el COVID-19: emite el } \\
\text { decreto de Toque de Queda; Segmentación de la población conforme a la } \\
\text { terminación de los dígitos de su tarjeta de identidad, pasaporte y/o carnet de } \\
\text { residentes, para que puedan abastecerse de alimentos, medicinas, combustibles y } \\
\text { realizar trámites; Queda prohibida la circulación de vehículos y salida de personas } \\
\text { a nivel nacional; Está prohibida la apertura de restaurantes, establecimientos de } \\
\text { comida rápida, cafés y otros similares dedicados a la venta de alimentos, }\end{array}$ \\
\hline
\end{tabular}




\begin{abstract}
incluyendo el servicio de entrega a domicilio; Durante la vigencia del toque de queda los supermercados, farmacias y gasolineras están autorizados a operar únicamente y sin excepción los días indicados; Se autoriza la circulación del transporte pesado de alimentos, combustible, insumos médicos, productos de exportación e importación, agroexportadores y otros necesarios para atender la emergencia nacional, siempre que cumplan con las medidas de bioseguridad recomendadas.

-Secretaría de Trabajo y Seguridad Social anuncia medidas para garantizar el mantenimiento de los empleos y la sostenibilidad productiva de las empresas: Autorizar a los trabajadores y empleadores del sector privado para que de común acuerdo convengan que los días feriados que señala el Código de Trabajo se consideren como otorgados y gozados por parte de los trabajadores durante el período de vigencia del Estado de Emergencia Sanitaria Nacional por la propagación del COVID19. Los empleadores podrán conceder a cuenta de vacaciones, los días que en virtud del Estado de Emergencia los trabajadores no se presenten a trabajar en su jornada ordinaria. Se exceptúa de lo anterior, la obligatoriedad del patrono de poner en conocimiento al trabajador, con diez días de anticipación el goce de sus vacaciones

-En materia tributaria: El Servicio de Administración de Rentas comunica que se continuarán atendiendo consultas y brindando asesoría a través del Contact Center: se amplían los plazos para presentación de ciertas declaraciones y de fecha límite de emisión de documentos fiscales; (SAYAGUÉS, 2020)
\end{abstract}

Fuente: Elaboración propia (2020).

\title{
-SIN IMPLEMENTACIÓN DE MEDIDAS FRENTE AL COVID-19: MÉXICO, NICARAGUA Y URUGUAY.
}

Tanto México como Nicaragua, tuvieron la particularidad de no implementar rápidamente las medidas o planes de emergencia adoptados por los demás países de América Latina y el Caribe manteniendo la normalidad en cuanto a obligaciones y trabajo, aunque México implemento fases de acuerdo a los casos que se vayan presentando.

GONZALEZ (2020) señaló en su reportaje que: "Frente a la tendencia general de clausurar fronteras y decretar encierros obligatorios para frenar la expansión del coronavirus, solo dos países en América Latina van a contracorriente de esta estrategia”. (s/p). Fueron países que aplicaron menos medidas restrictivas frente a la Pandemia.

El Gobierno Nicaragüense no ha dispuesto medidas especiales a la fecha, por lo que las obligaciones tributarias formales y materiales, las mantienen según lo dispuesto en sus normas internas; de igual forma, todo plazo se encuentra corriendo a la fecha. En ese sentido, el Gobierno hace un llamado a que las Compañías tomen las medidas necesarias con el fin de atender cualquier notificación o requerimiento de información por parte de las Autoridades, especialmente en aquellas donde se hayan dispuesto medidas de teletrabajo o similares. (SAYAGUÉS, 2020). 
El gobierno Mexicano indicó que cada medida se implementará en su debido momento pero, ante las críticas, ya adelantó parte de la fase 2 de su plan de contingencia previsto para un escenario con cientos de contagios. Como consecuencia, todas las escuelas están cerradas y se dio inicio a una "jornada nacional de sana distancia" por un mes, en la que se recomienda a las empresas suspender actividades no esenciales o permitir que se hagan desde casa de manera remota, así como reprogramar eventos masivos. No fue sin embargo hasta el 19 de marzo de 2020 que el gobierno recomendó (no obligó) de manera pública a la población que se quedara en casa "si no es indispensable" salir. (GONZÁLEZ, 2020).

Para México, la fase 1 los casos son sólo de decenas, todos de importación o de contactos con esos afectados (ámbito familiar). La fase 2 ya es dispersión comunitaria, con contagios generados en la comunidad, pero todavía focalizados. La 3 es la epidémica, con miles de casos en todo el país. El subsecretario de Salud Hugo López Gatell, explicó, que a diferencia de otros países como China, Italia o Estados Unidos, que son de las economías más grandes, en México, aunque es la número 14 en el mundo, la desigualdad hace imposible que las medidas de resguardo como la cuarentena o la restricción de movilidad se endurezcan. México llegará a la fase 3 de COVID19, la epidémica, y lo hará en aproximadamente 15 días según información del subsecretario de Prevención y Promoción de la Salud.

Uruguay fue un caso muy particular, un país que nunca impuso confinamientos obligatorios y se consideró como un caso de éxito en la gestión de la crisis del coronavirus; la tasa de contagios se mantuvo baja y el sistema de salud nunca llegó a verse comprometido, el país se mantuvo en sus actividades habituales. (BBC NEWS MUNDO, 2020)

\section{CONSIDERACIONES FINALES}

Como se observó en las comparativas de los planes tomados por los países, muchos de ellos aprobaron leyes de emergencia y han tomado medidas que restringen la libertad de circulación, asociación, expresión y reunión pública, así como el derecho a la vida privada y familiar y el derecho a trabajar. Aunque algunas medidas de emergencia están justificadas, no los exime a cumplir que las medidas sean legales, necesarias y proporcionadas, que son temporales dada la situación y que están sujetas a una supervisión y revisión independientes; además no deben utilizarse como pretexto para negar la entrada a las personas refugiadas. Debe reconocerse el derecho a solicitar asilo, y no se debe devolver a las personas a lugares en los que pueda correr 
peligro de sufrir violaciones graves de derechos humanos, como actualmente está ocurriendo con muchos venezolanos que en estos momentos se encuentran pasando la frontera con Colombia para llegar a Venezuela motivado a que han sido expulsados de sus viviendas por no honrar el compromiso del pago del alquiler en virtud de las medidas de suspensión de los contratos de trabajo en el exterior.

Los Expertos de la ONU consideran que las restricciones a las libertades ciudadanas deben ser consideradas transitorias, y que deben ser aplicadas solo en el contexto de la pandemia. Cualquier respuesta de emergencia al coronavirus debe cumplir con los criterios establecidos: ser proporcionada, necesaria, no discriminatoria y no deben usarse como base para atacar a grupos particulares, minorías o individuos; además, no debe funcionar como una excusa para la acción represiva bajo pretexto de proteger la salud.

La Oficina del Alto Comisionado de las Naciones Unidas emitió en su página web un comunicado oficial sobre el llamado a los Estados a no abusar o extralimitarse de las medidas de seguridad que impongan. Reconocen que el uso de los poderes en casos de emergencia es permitido por el derecho internacional en respuesta a amenazas significativas, pero se debe colocar los derechos humanos en el centro de la respuesta al brote del coronavirus.

Amnistía Internacional, por otro lado, ha publicado una serie de recomendaciones para los Estados de Europa en las que los insta a garantizar que sus respuestas a la COVID-19, sean conformes con sus obligaciones internacionales y regionales en materia de derechos humanos. Europe at a Crossroads establece unas directrices claras sobre lo que los gobiernos deben y no deben hacer en respuesta a la actual pandemia. Entre ellas se encuentra garantizar el derecho de las personas a la salud (para lo cual es necesario garantizar el derecho a la vivienda, el agua y el saneamiento) y garantizar la protección de los sectores más vulnerables de la sociedad. El acceso a la información es otro de los aspectos claves del derecho a la salud. Todas las personas tienen derecho a ser informadas de las medidas de respuesta adoptadas. No garantizar este derecho debilita la respuesta de los servicios de salud pública y pone en riesgo la salud de todo el mundo. No se sabe a ciencia cierta si Venezuela comunica cifras reales de la situación del COVID-19.

Lamentablemente en estos momentos, los grupos vulnerables (solicitantes de asilo, refugiadas y migrantes) que se encuentran en campos masificados, corren un mayor riesgo de contagiarse, por lo tanto urge que los Estados los protejan, incluso los que no tiene un hogar y los que están privados de libertad en prisiones, centros de detención para inmigrantes u otro tipo de instituciones. El Papa Francisco en su oración "Urbi et Orbi", en la misa de Domingo de Resurrección (12 de abril de 2020) suplicó que se "reconforte el corazón de tantas personas 
refugiadas y desplazadas a causa de guerras, sequías y carestías. Que proteja a los numerosos migrantes y refugiados -muchos de ellos son niños-, que viven en condiciones insoportables, especialmente en Libia y en la frontera entre Grecia y Turquía" pidió además que sea eliminadas las sanciones internacionales que pesan sobre algunos países y también abogó por la condonación de las deudas. (TELESUR, 2020)

En esta situación de crisis sanitaria, la cooperación internacional y la solidaridad son decisivas. Los gobiernos con capacidad económica y técnica para hacerlo, deben ayudar a los que tengan menos recursos para estar preparados para enfrentar los brotes. Igualmente, los Estados deben proporcionar a otros Estados y a las organizaciones internacionales información pertinente sobre el grado de propagación del COVID-19 en sus territorios, sus consecuencias, y la información de que dispongan sobre su posible tratamiento. Esta crisis coloca además de forma palpable, la interconexión entre la exclusión, la desigualdad y las violaciones de derechos humanos. Pero también brinda a los gobiernos la oportunidad de realizar los cambios radicales que se necesitan para ser una sociedad ideal, que respeta y coloca los derechos humanos sobre cualquier medida que se adopte.

\section{REFERENCIAS BIBLIOGRÁFICAS}

ALGARRA, Álvaro. (2020, Marzo 17). Venezuela: aumentan medidas sanitarias en mercados por COVID-19. Voz de América. [Consulta Abril 8, 2020]. Recuperado de: https://www.voa noticias.com/a/venezuela-aumentan-medidas-sanitarias-en-mercados-por-covid-19-/5351897.html

AMNISTÍA INTERNACIONAL. (2020, Abril 2). Américas: Los gobiernos deben poner fin a las detenciones peligrosas y discriminatorias de migrantes y solicitantes de asilo. [Consulta Abril 8, 2020]. Recuperado de: https://www.es.amnesty.org/en-que-estamos/noticias/noticia/articulo/ame ricas-los-gobiernos-deben-poner-fin-a-las-detenciones-peligrosas-y-discriminatorias-de-migrantes/

AMNISTÍA INTERNACIONAL. (2020, Marzo 25). AI presenta un decálogo de derechos humanos para afrontar la pandemia del coronavirus. [Consulta Abril 7, 2020]. Recuperado de: https://www.es.amnesty.org/en-que-estamos/noticias/noticia/articulo/amnistia-internacionalpresenta-un-decalogo-de-derechos-humanos-para-afrontar-la-pandemia/

AMNISTÍA INTERNACIONAL. (2020, Abril 3). Rusia: Las autoridades detienen a la doctora que denunció deficiencias en la respuesta al coronavirus. [Consulta Abril 8, 2020]. Recuperado de: https://www.es.amnesty.org/en-que-estamos/noticias/noticia/articulo/rusia-las-autoridades-detienena-la-doctora-que-denuncio-deficiencias-en-la-respuesta-al-coronavirus/

AMNISTÍA INTERNACIONAL. (2020, Abril 2). Los Estados deben respetar los derechos humanos al emplear tecnologías de vigilancia digital para combatir la pandemia. [Consulta Abril 8, 2020]. Recuperado de: https://www.es.amnesty.org/en-que-estamos/noticias/noticia/articulo/los-estadosdeben-respetar-los-derechos-humanos-al-emplear-tecnologias-de-vigilancia-digital-para-co/ 
AMNISTÍA INTERNACIONAL. (2020, Abril 2). Europa: Prioridades de derechos humanos para los Estados en su respuesta al coronavirus. [Consulta Abril 8, 2020]. Recuperado de: https://www.es.amnesty.org/en-que-estamos/noticias/noticia/articulo/europa-prioridades-dederechos-humanos-para-los-estados-en-su-respuesta-al-coronavirus/

BBC NEWS MUNDO. (2020, Mayo 29). Coronavirus en Uruguay: la singular y exitosa estrategia del país para contener la pandemia sin cuarentena obligatoria. [Consulta Abril 7, 2020]. Recuperado de: https://www.bbc.com/mundo/noticias-america-latina-52837193

CHIRINOS, Mariengracia. (2020, Marzo 25). Derechos humanos para atender la pandemia de COVID-19. [Consulta Abril 7, 2020]. Recuperado de: https://prodavinci.com/derechos-humanos-paraatender-la-pandemia-de-covid-19/

COMISIÓN INTERAMERICANA DE DERECHOS HUMANOS (CIDH). (2020, Marzo 20). La CIDH y su REDESCA instan a asegurar las perspectivas de protección integral de los derechos humanos y de la salud pública frente a la pandemia del COVID-19. Organización de Estados Americanos. Prensa, comunicados Recuperado de http://www.oas.org/es/cidh/prensa/comunicados/2020/060.asp

GONZÁLEZ Díaz, Marcos. (2020, Marzo 27). Coronavirus: por qué México y Nicaragua son los países de América Latina con menos medidas restrictivas frente al covid-19. Corresponsal de BBC News Mundo en México y Centroamérica. [Consulta Abril 8, 2020]. Recuperado de: https://www.bbc.com/mundo/noticias-america-latina-52059566

HUMAN RIGHTS WATCH.ORG. (2020, Marzo 31). Dimensiones de derechos humanos en la respuesta al COVID-19. Hora: 4:32 PM EDT. [Consulta Abril 7, 2020]. Recuperado de: https://www.hrw.org.

MALAMUD, Carlos; NÚÑEZ, Rogelio. (2020, Marzo 17). El COVID-19 en América Latina: desafios políticos, retos para los sistemas sanitarios e incertidumbre económica. ARI 27/2020 - 17/3/2020. Real Instituto El Cano. [Consulta Abril 10, 2020]. Recuperado de: http://www.realinstitutoelcano.org/wps/portal/rielcano_es/contenido?WCM_GLOBAL_CONTEXT= /elcano/elcano_es/zonas_es/ari27-2020-malamud-nunez-covid-19-en-america-latina-desafiospoliticos-retos-sistemas-sanitarios-e+incertidumbre-economica

NATERA Febres, David. (2020, Marzo 22). Medidas económicas del gobierno para encarar emergencia del Covid-19 sobrecargan al sector privado. Correo del Caroní. [Consulta Abril 7, 2020]. Recuperado de: https://www.correodelcaroni.com/salud/coronavirus/4795-maduro-confirmo-77casos-de-coronavirus-y-medidas-economicas-que-recaen-en-el-sector-\%E2\%80\% A6

OFICINA DEL ALTO COMISIONADO DE LAS NACIONES UNIDAS. (2020a, Marzo 6). Coronavirus: La respuesta debe basarse integramente en los derechos humanos, afirma Bachelet. Noticias COVID-19. [Consulta Abril 7, 2020]. Recuperado de: http://www.oacnudh.org/coronavirusla-respuesta-debe-basarse-integramente-en-los-derechos-humanos-afirma-bachelet/

OFICINA DEL ALTO COMISIONADO DE LAS NACIONES UNIDAS (2020b, Abril 27). Las Medidas de Emergencia y el COVID-19: Orientaciones. [Consulta Abril 30, 2020]. Recuperado de: https://www.ohchr.org/Documents/Events/EmergencyMeasures_COVID19_ES.pdf 
OFICINA DEL ALTO COMISIONADO PARA LAS NACIONES UNIDAS. (2020c, Marzo 23). No se podrá parar el COVID-19 sin proporcionar agua a las personas en situación de vulnerabilidadExpertos de la ONU. [Consulta Abril 7, 2020]. Recuperado de: https://www.ohchr.org/SP/NewsEvents/Pages/DisplayNews.aspx?NewsID=25738\&LangID=S

ORGANIZACIÓN DE LAS NACIONES UNIDAS (ONU). (2020, Agosto 11). CONSEJO ECONÓMICO Y SOCIAL. El derecho al disfrute del más alto nivel posible de salud: 11/08/2000. E/C.12/2000/4, CESCR OBSERVACION GENERAL 14. (General Comments). [Consulta Abril 7, 2020]. Recuperado de: https://www.acnur.org/fileadmin/Documentos/BDL/2001/1451.pdf

ORGANIZACIÓN DE LAS NACIONES UNIDAS (ONU). (2020, Marzo 19) RELATORIA ESPECIAL PARA LA LIBERTAD DE EXPRESIÓN (2020). Comunicado de prensa R58/20: COVID-19: Los gobiernos deben promover y proteger el acceso y la libre circulación de la información durante la pandemia - Expertos internacionales. [Consulta Abril 7, 2020]. Recuperado de: https://www.oas.org/es/cidh/expresion/showarticle.asp?artID=1170\&lID=2

SAYAGUÉS, Rafael. (2020, Marzo 17). Medidas especiales de los gobiernos de Centroamérica respecto a COVID-19. EY Building a better working world. Actualizado al Abril 3, 2020. [Consulta Abril 7, 2020]. Recuperado de: https://www.ey.com/es_cr/tax/medidas-especiales-covid-19

UNITED NATIONS HUMAN RIGHTS. Office of the High Commissioner. (2020, Marzo 16). COVID-19: States should not abuse emergency measures to suppress human rights - UN experts. Ginebra. [Consulta Abril 7, 2020]. Recuperado de: https://www.ohchr.org/EN/NewsEvents/Pages/DisplayNews.aspx?NewsID=25722\&LangID=E

TELESUR, (2020, Abril 12). El Papa pide eliminación de sanciones y condonación de la deuda. TeleSUR - JGN, Noticias Mundo. [Consulta Abril 12, 2020]. Recuperado de: https://www .telesurtv.net/news/papa-francisco-mensaje-urbi-orbi-pascua-pandemia-20200412-0006.html

TOMASINO, Erick. (2020, Marzo 27). El Salvador: Covid-19 y estado de excepción. [Consulta Abril 7, 2020]. Fuente: Rebelión. América Latina y Caribe. Recuperado de: https://rebelion.org/covid-19-yestado-de-excepcion/

VIERA Rivas, Romer. (2020, Marzo 25). Activado plan especial de pago de nóminas para pequeñas, medianas empresas y comercios. Edición Impresa: Correo del Orinoco, pagina 2. Número 3.739. [Consulta Abril 8, 2020]. Recuperado de: http://www.correodelorinoco.gob.ve/wp-content/uploads /2020/03/Edici\%C3\%B3n-Impresa-Correo-del-Orinoco-N\%C2\%B0-3739-Mi\%C3\%A9rcoles-25-deMarzo-de-2020-1.pdf

Trabalho recebido em 30 de abril de 2020 Aceito em 23 de agosto de 2021 